\title{
Distribution of PD-1+ Lymphocytes in Reactive Lymphadenopathies
}

\author{
Simone Muenst Stephan Dirnhofer Alexandar Tzankov \\ Institute of Pathology, University Hospital, Basel, Switzerland
}

\section{Key Words}

Angioimmunoblastic T-cell lymphoma · PD-1 - Reactive lymphadenopathies

\begin{abstract}
Objectives: Programmed death-1 (PD-1) is physiologically expressed by germinal center (GC)-associated helper T cells. It has been proposed that an increase in PD-1+ cells outside GC could indicate pattern I angioimmunoblastic T-cell lymphoma (AITL). Methods: We studied the distribution of PD$1+$ cells in reactive lymphadenopathies (LA), including HIVassociated and dermatopathic LA ( $n=5$, each), Castleman $(n=3)$, Kikuchi $(n=2)$ and Rosai-Dorfman diseases $(n=1)$, sarcoidoses $(n=7)$ and follicular hyperplasias $(n=8)$. Results: The highest concentrations of PD-1+ cells in GC were found in Castleman and Rosai-Dorfman diseases (mean 57 and $50 \%$ of total cells, respectively), and the lowest in HIV-associated LA (mean 6\%). The highest proportions in paracortices were found in Castleman disease, and in HIV-associated and dermatopathic LA (mean 7, 3 and 2\%, respectively). PD-1+ cells predominated in the pale zones of GC in follicular hyperplasia. In HIV-associated LA, PD-1+ cells showed marked marginalization in the GC. No paracortical PD-1+ cells were found in sarcoidoses and Rosai-Dorfman disease. Conclusions: The varying distribution of PD-1+ cells in defined LA
\end{abstract}

might indicate a functional relevance of these cells in the respective entities. Since increased numbers of PD-1+ cells outside $G C$ are observed in various $L A$, this finding might not be entirely specific for pattern I AITL.

Copyright $\odot 2010$ S. Karger AG, Basel

\section{Introduction}

Programmed death-1 (PD-1) is a member of the CD28 costimulatory receptor superfamily. It is expressed on a subset of thymocytes and is upregulated on activated $\mathrm{T}$, B and myeloid cells. Dorfman et al. [1] found that PD-1 is specifically expressed by germinal center (GC)-associated $\mathrm{T}$ cells in reactive lymphoid tissue as well as by tumor cells in angioimmunoblastic T-cell lymphoma (AITL).

PD-1 inhibits T-cell activity via a negative signal to $\mathrm{T}$ cells in conjunction with signaling through the T-cell receptor. Recent studies indicate that PD-1 functions as a negative regulator of the immune system and is important in peripheral tolerance [2]. There are at least two ligands for PD-1, PD-L1 and PD-L2. PD-L-PD-1 interactions lead to cell cycle arrest in $\mathrm{G}_{0} / \mathrm{G}_{1}$ but do not increase cell death. PD-L1 engagement of PD-1 on T cells inhibits activation of these cells. Engagement of PD-1 by PD-L2 dramatically inhibits T-cell receptor-mediated prolifera-

\section{KARGER}

Fax +4161306 1234

E-Mail karger@karger.ch

www.karger.com (c) 2010 S. Karger AG, Basel

1015-2008/10/0771-0024\$26.00/0

Accessible online at:

www.karger.com/pat
PD Dr. A. Tzankov

Institute of Pathology, University Hospital Basel

Schönbeinstrasse 40

$\mathrm{CH}-4031$ Basel (Switzerland)

Tel. +41 61265 2757, Fax +41 61265 3194, E-Mail atzankov@ uhbs.ch 
Table 1. Distribution of $\mathrm{PD}-1+$ cells in reactive $\mathrm{LA}$

\begin{tabular}{lcccl}
\hline \multirow{2}{*}{ Disease } & \multicolumn{2}{l}{ Proportion of PD-1+cells, $\%$} & \multirow{2}{*}{ Remark } \\
\cline { 2 - 3 } & GC & $\begin{array}{l}\text { mantle } \\
\text { zones }\end{array}$ & paracortex & \\
\hline Castleman disease & $57 \pm 20$ & $10 \pm 17$ & $7 \pm 11$ & \\
Dermatopathic LA & $25 \pm 5$ & $1 \pm 0.8$ & $2 \pm 2$ & scattered between monocytoid cells \\
Follicular hyperplasia & $22 \pm 21$ & $1 \pm 2$ & $1 \pm 2$ & abundant in pale zones of GC \\
HIV-associated LA & $6 \pm 4$ & $7 \pm 3$ & $3 \pm 1$ & marked marginalization in GC \\
Kikuchi disease & $23 \pm 4$ & $6 \pm 6$ & $0.3 \pm 0.4$ & absent in necrosis zones \\
Rosai-Dorfman disease & 50 & 2 & 0 & \\
Sarcoidosis & $32 \pm 14$ & $2 \pm 4$ & 0 & \\
\hline
\end{tabular}

tion and cytokine production by CD4+ cells [3]. It has been shown that PD-1 is selectively upregulated by exhausted $\mathrm{T}$ cells during chronic viral infection such as HIV. Blockade of PD-1-related pathways restores CD8+ T-cell functions and reduces viral load [4].

It has been proposed that an increase in PD-1+ cells outside GC could be a precursor lesion of AITL $[5,6]$. The aim of our study was to determine the distribution of PD$1+$ cells, particularly their appearance outside GC, in various reactive lymphadenopathies (LA).

\section{Material and Methods}

Thirty-one samples of various LA were collected from the archives of the Institute of Pathology at the University Hospital of Basel. All were reevaluated and the initial diagnosis was confirmed: dermatopathic LA $(n=5)$, Castleman disease of the hyaline-vascular type, all HIV negative $(\mathrm{n}=3)$, Kikuchi disease $(\mathrm{n}=$ $2)$, Rosai-Dorfman disease $(n=1), H I V$-associated LA $(n=5)$, sarcoidoses $(n=7)$ and follicular hyperplasias $(n=8)$.

\section{Immunohistochemistry}

Immunohistochemical staining of formalin-fixed and paraffin-embedded tissue was performed. Slides were stained manually. Heat-induced (autoclave) antigen retrieval in citrate buffer (pH 6.0) for $10 \mathrm{~min}$ at $120^{\circ} \mathrm{C}$ was performed and the streptavidinbiotin-peroxidase detection technique was applied with aminoethylcarbazole as chromogen. The primary goat anti-human PD-1 antibody (AF 1086; R \& D Systems, Germany) was diluted $1: 40$ in a $1 \%$ solution of bovine serum albumin in PBS (pH 7.4) and the slides were incubated overnight at $4^{\circ} \mathrm{C}$. The percentage of $\mathrm{PD}$ $1+$ cells in relation to all background cells in different lymph node areas was determined considering at least 5 microscopic fields $\left(5 \times 1.33 \mathrm{~mm}^{2}\right)$ at 200 -fold magnification. Scoring was performed on a double-headed microscope by two of us (S.M. and A.T.). Reproducibility was assessed by rescoring of the samples by one of us (A.T.) and estimated by interclass correlation coefficients, using reliability analysis (Cronbach's $\alpha$ ).

PD-1+ Lymphocytes in Reactive Lymphadenopathies

\section{Results}

PD-1+ cell quantization was reproducible (average interobservation correlation coefficient 0.92 ), being excellent $(\alpha=1)$ in samples with fewer PD-1+ cells, e.g. sarcoidoses, Kikuchi and Rosai-Dorfman diseases, and good $(\alpha=0.84)$ in HIV-associated and dermatopathic LA. The distribution of PD-1+ cells varied considerably between the different reactive LA (table 1; fig. 1). The highest percentages of PD-1+ cells in GC were found in Castleman and Rosai-Dorfman disease (mean 57 and $50 \%$ of total cells, respectively), and the lowest percentage in HIV-associated LA (mean 6\%). The highest percentage in paracortices near the mantle zones were found in Castleman disease, and HIV-associated and dermatopathic LA (mean 7, 3 and 2\%, respectively). PD-1+ cells were located between monocytoid $\mathrm{B}$ cells in hyperplastic marginal zones, between Langerhans' cells in dermatopathic LA and in the pale GC zones in follicular hyperplasia. In HIV-associated LA, PD-1+ cells showed a marked marginalization in GC. No PD-1+ cells were found in the paracortices of lymph nodes with sarcoidosis and RosaiDorfman disease and in the necrosis zones of Kikuchi disease.

\section{Discussion}

In our study, we demonstrate varying distribution of PD-1+ cells in defined LA. Clusters of PD-1+ neoplastic cells in perifollicular areas and around high endothelial venules in the expanded paracortex of lymph nodes have been proposed as a diagnostic criterion for pattern I AITL $[1,5,6]$. However, since markedly increased numbers of PD-1+ cells are also found in the paracortex of lymph 


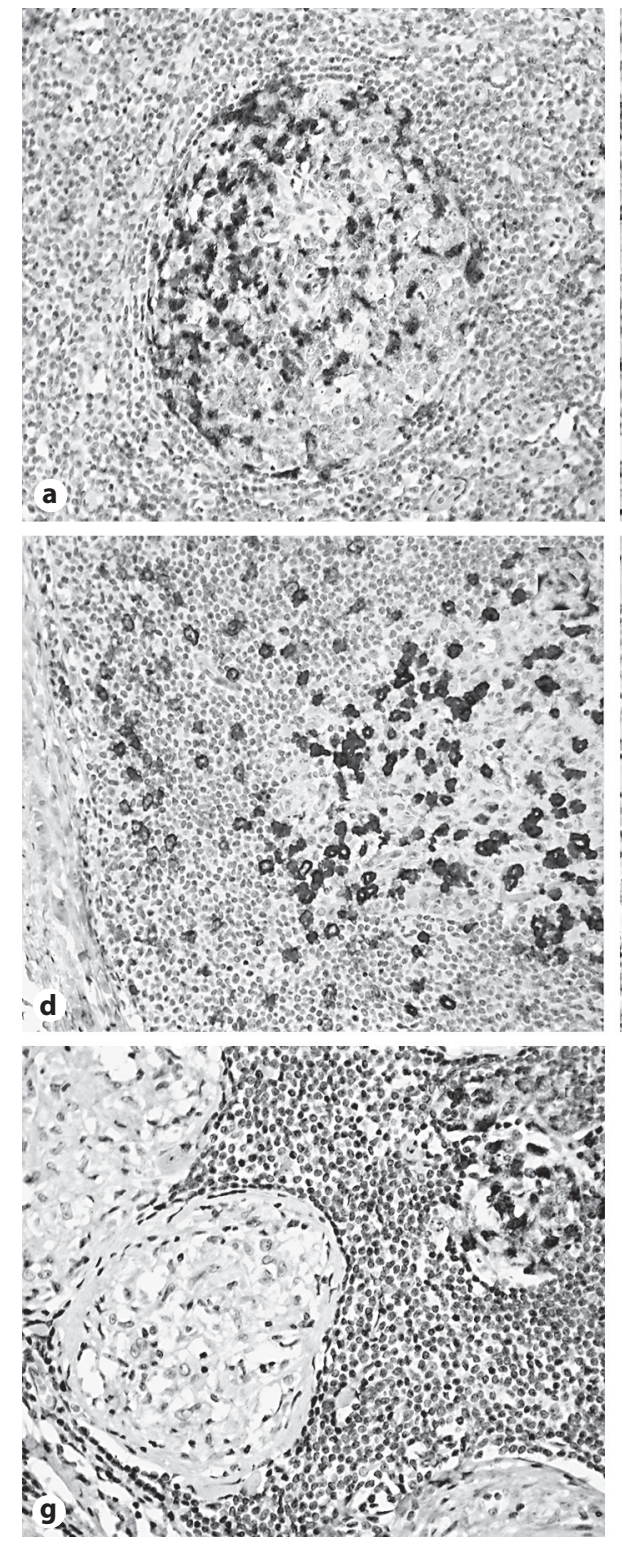

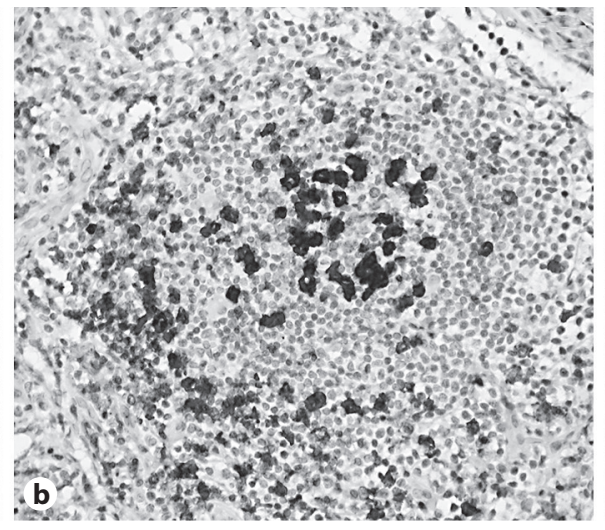
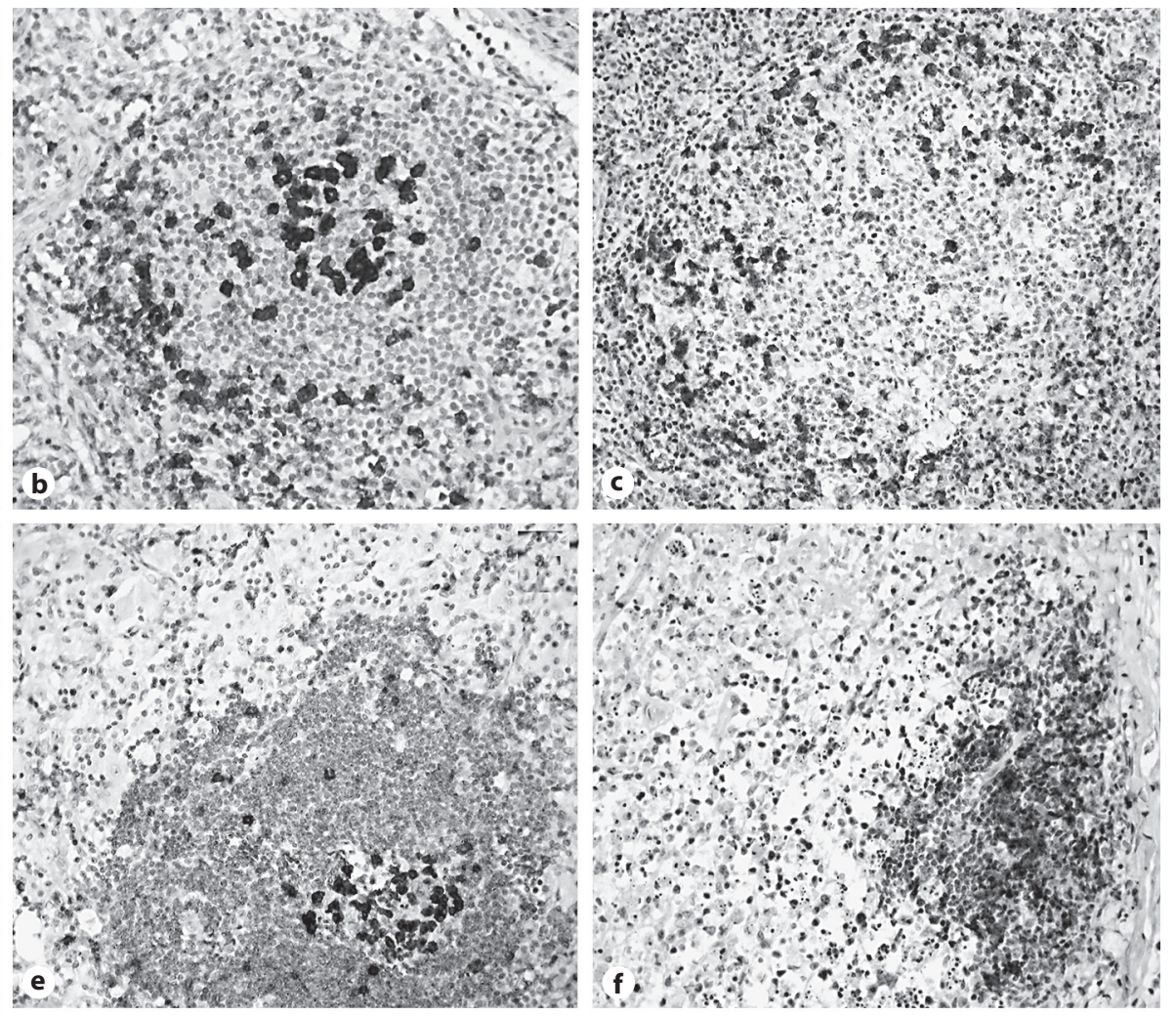

Fig. 1. a PD-1+ cells in a hyperplastic GC of follicular hyperplasia. Note the abundance of PD- $1+$ cells in the pale zone. $\times 100$. $\mathbf{b}$ PD $-1+$ cells in a typical small involuting GC of hyaline-vascular Castleman disease. Note the persistence of PD-1+ cells despite GC Bcell depletion, and their increased numbers in mantle zones and the paracortices near the mantle zones. $\times 160$. c Marked depletion inside and marginalization of PD-1+ cells beneath the mantle zones of hyperplastic GC of HIV-associated LA type A. $\times 80$. d Increased numbers of PD-1+ cells between monocytoid cells in hyperplastic marginal zones and between Langerhans cells in dermatopathic LA. $\times 100$. No PD-1+ cells in the paracortex of lymph nodes with Rosai-Dorfman disease (e), in necrotic zones of Kikuchi disease (f) and in sarcoidosis $(\mathbf{g})$. Note retained PD-1+ cells in regressed GC. $\times 100$.

nodes with Castleman disease, and HIV-associated and dermatopathic LA, this finding should not be regarded as absolutely specific for pattern I AITL and these three conditions might be of relevance to be considered in the differential diagnosis. Beyond presence of PD-1+ cell clusters outside GC, the diagnosis of pattern I AITL should be corroborated, as suggested by Rodriguez-Justo et al. [6], by the typical morphological appearance and presence of Epstein-Barr virus-infected B (immuno)blasts. Since Castleman disease and AITL are accompanied by immune control deregulation $[7,8]$, the increased numbers of extrafollicular PD-1+ cells in the former, analo- gously to the neoplastic PD-1+ cells of AITL, might be of functional relevance in that instance.

In HIV-associated LA, the number of PD-1+ cells in GC was low, with a marked marginalization beneath the mantle zones. Recent data show that PD-1 is significantly upregulated on killer T cells that recognize HIV antigens in the peripheral blood of HIV-infected patients. This seems to exhaust $\mathrm{T}$ cells, which no longer perform vital functions to control viral infection [9]. While the proportion of killer T cells expressing PD-1 is markedly increased in the peripheral blood of HIV-infected patients, depletion was noted inside the GC and distinct 
follicular marginalization beneath the mantle zones of the PD-1+ T-follicular helper cells in HIV-associated LA. The functional importance of these PD-1+ cell redistribution patterns, though likely being of relevance, e.g. for abnormal B-cell function in HIV infection [10], remains to be elucidated.

While there is a general increase in the CD4+/CD8+ ratio in lymph nodes in sarcoidosis, this increase does not apply to the PD-1+ (CD4+) T cells in the T-cell zones.
Since PD-1+ T cells have an inhibitory effect on other T cells, this lacking increase in PD-1+ cells in the paracortices could be of relevance for the expansion of other CD4+ T cells, e.g. in granuloma formation [11].

To summarize, the varying distribution of PD-1+ cells in defined LA could indicate their functional relevance in the respective entities. Since increased numbers of PD- $1+$ cells outside GC are also found in various LA, this finding is not entirely specific for pattern I AITL.

\section{References}

1 Dorfman DM, Brown JA, Shahsafaei A, Freeman GJ: Programmed death-1 (PD-1) is a marker of germinal center-associated $\mathrm{T}$ cells and angioimmunoblastic T-cell lymphoma. Am J Surg Pathol 2006;30:802-810.

$\checkmark 2$ Probst HC, McCoy K, Okazaki T, Honjo T, van den Broek M: Resting dendritic cells induce peripheral CD $8+\mathrm{T}$ cell tolerance through PD-1 and CTLA-4. Nat Immunol 2005;6:280-286.

-3 Latchman Y, Wood CR, Chernova T, Chaudhary $\mathrm{D}$, Borde $\mathrm{M}$, Chernova I, Iwai Y, Long AJ, Brown JA, Nunes R, Greenfield EA, Bourque K, Boussiotis VA, Carter LL, Carreno $\mathrm{BM}$, Malenkovich $\mathrm{N}$, Nishimura $\mathrm{H}$, Okazaki T, Honjo T, Sharpe AH, Freeman GJ: PD-L2 is a second ligand for PD-1 and inhibits T cell activation. Nat Immunol 2001; 2:261-268.
Barber DL, Wherry EJ, Masopust D, Zhu B, Allison JP, Sharpe AH, Freeman GJ, Ahmed $\mathrm{R}$ : Restoring function in exhausted CD8 T cells during chronic viral infection. Nature 2006;439:682-687.

$>5$ Roncador G, García Verdes-Montenegro JF, Tedoldi S, Paterson JC, Klapper W, Ballabio E, Maestre L, Pileri S, Hansmann ML, Piris MA, Mason DY, Marafioti T: Expression of two markers of germinal center T cells (SAP and PD-1) in angioimmunoblastic T-cell lymphoma. Haematologica 2007;92:10591066.

6 Rodriguez-Justo M, Attygalle AD, Munson P, Roncador G, Marafioti T, Piris MA: Angioimmunoblastic T-cell lymphoma with hyperplastic germinal centres: a neoplasia with origin in the outer zone of the germinal centre? Clinicopathological and immunohistochemical study of 10 cases with follicular T-cell markers. Mod Pathol 2009;22:753761.
Shahidi H, Myers JL, Kvale PA: Castleman's disease. Mayo Clin Proc 1995;70:969-977.

$>$ Casper C: The aetiology and management of Castleman disease at 50 years: translating pathophysiology to patient care. Br J Haematol 2005; 129:3-17.

9 Rowland-Jones S, Dong T: HIV: tired T cells turn around. Nature 2006;443:282-283.

10 De Milito A: B lymphocyte dysfunctions in HIV infection. Curr HIV Res 2004;2:11-21.

11 Grunewald J, Eklund A: Role of CD4+ T cells in sarcoidosis. Proc Am Thorac Soc 2007;4: 461-464. 